\title{
ACUTE SUPRAMAXIMAL EXERCISE-INDUCED ADIPONECTIN INCREASE IN HEALTHY VOLUNTEERS: INVOLVEMENT OF NATRIURETIC PEPTIDES
}

\author{
Gülnur Öztürka, Oktay Kaya ${ }^{b}$, Elif Ezgi Gürel ${ }^{b}$, Orkide Palabiyikc, Hakan Kunduracilard, Necdet Süte, \\ Levent Öztürk ${ }^{b}$, and Selma Arzu Vardar \\ aDepartment of Physiotherapy and Rehabilitation, Trakya University Faculty of Health Sciences, Edirne, Turkey and

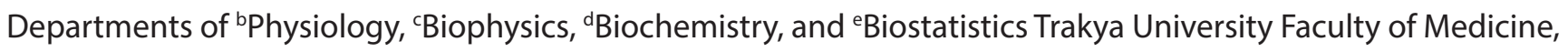 \\ Edirne, Turkey
}

\begin{abstract}
Exercise may modulate lipolysis via leading to natriuretic peptide secretion and beta-adrenergic activation. Adiponectin, an adipose-secreted multifunctional signaling protein, may be the missing link between exercise and lipolytic activity. In this study, we aimed to investigate the effects of supramaximal exercise on plasma levels of adiponectin, atrial natriuretic peptide (ANP), and Btype natriuretic peptide (BNP) in healthy humans. Thirty-one healthy young adult volunteers (male/female, 15/16; mean age \pm SD, 20.7 \pm 1.7 years) underwent a 30-second Wingate anaerobic exercise test on a cycle ergometer and venous blood sampling before and after the exercise test. Plasma ANP and BNP levels were assayed by radioimmunoassay, whereas adiponectin levels were assayed by enzyme-linked immunosorbent assay. Systolic and diastolic blood pressures, heart rate, hematocrit levels and blood lactate were also measured before and after exercise. The mean plasma adiponectin level significantly increased following a 30-second anaerobic exercise test compared to resting level $(17.45 \pm 4.70$ vs $31.29 \pm 5.16 \mu \mathrm{g} / \mathrm{mL}$, respectively, $p<0.001)$. The mean plasma ANP and BNP levels remained comparable before and after the 30-second anaerobic exercise. A 30-sec supramaximal exercise session enhanced circulating adiponectin levels in both gender groups, whereas ANP and BNP levels exerted nonsignificant alterations. We suggest that acute anaerobic exercise may affect secretory function of adipose tissue which seems not related with natriuretic peptide secretion.
\end{abstract}

Adipobiology 2016, 8: 39-45

Key words: anaerobic exercise, adiponectin, natriuretic peptides 


\section{Introduction}

The cardiac natriuretic hormones comprise of atrial natriuretic peptide (ANP), B-type natriuretic peptide (BNP), C-type natriuretic peptide (CNP), dendroaspis natriuretic peptide (DNP) and urodilatin. These peptides share some common structural and biologic properties such as diuresis, natriuresis, vasodilation and inhibition of ventricular myosites. Their activities may also differ to some extent. ANP is released from atrial cardiomyocytes in response to intra-atrial pressure increase and BNP is released from ventricular cardiomyocytes in response to stretching and myocardial ischemia or damage (1). Elevated plasma BNP levels in patients with chronic cardiac failure have been suggested as the marker of ventricular ejection fraction and exercise capacity (2). Dynamic exercise increases BNP levels in patients with heart failure $(3,4)$. BNP levels may also increase in marathon runners during long-term strenuous exercise (5). On the other hand, blood BNP was within normal levels in football players and there was no relationship between left ventricular hyperthrophy, blood BNP and cardiac troponin C (6).

Recent studies revealed lipid mobilization and lipolysis effects of natriuretic peptides on adipocytes $(7,8)$. ANP and BNP play role in the regulation of lipolysis in isolated adipocytes through binding A-type guanylyl cyclase receptor and activating hormone-sensitive lipase (9). In addition, exercise may modulate lipolysis via leading to natriuretic peptide secretion and beta-adrenergic activation. Thus, adiponectin may be the missing link between exercise and lipolytic activity. The relationship of adiponectin and natriuretic peptides seems to be more complicated. Exogenous ANP administration resulted in elevation of plasma adiponectin levels of patients with heart failure (10). In a study, NT-proBNP and adiponectin levels were in positive correlation (11).

In this study, we tested the hypothesis that an acute supramaximal exercise bout alters plasma ANP, BNP and adiponectin levels in healthy female and male subjects. We also investigated the relationship between blood pressure, adiponectin, ANP, BNP, lactate and hematocrit levels.

\section{Materials and Methods}

\section{Study group}

Study protocol was approved by local ethics committee and all procedures performed were in accordance with the ethical standards of the institutional and/or national research committee and with the 1964 Helsinki declaration and its later amendments or comparable ethical standards. Thirtyone healthy young adult volunteers (M/F, 15/16; mean age $\pm S D, 20.7 \pm 1.7$ years) were included to the study. Baseline evaluations included physical examination, electrocardiography, complete blood count and blood biochemistry including fasting blood glucose, urea, creatinin, liver enzymes, and serum lipid profile. Exclusion criteria were positive family history for heart diseases, pathological findings in electrocardiography such as arrhythmia and long QT, hypertension, musculoskeletal disorders, renal or hepatic dysfunction, peripheral vascular diseases, dyslipidemia, and regular medications. All participants underwent a 30-sec supramaximal exercise test by Wingate protocol. Pre- and post-exercise systolic and diastolic blood pressures (SBP and DBP), blood lactate and hematocrit levels were measured. Post-exercise measurements were performed within the 5 th minute after the Wingate exercise test. Venous blood samples were collected from antecubital vein into tubes with anticoagulant before and after exercise session. After cold centrifugation at $3000 \mathrm{rpm}$ for 10 minutes, plasma samples aliquoted into Eppendorf tubes and stored at $-80^{\circ} \mathrm{C}$ until assay.

\section{Supramaximal exercise test}

The Wingate test comprised of a 30-sec supramaximal cycling against a resistance load. Test protocol can be find elsewhere (12). In brief, each test was performed on a cycle ergometer (Ergomedic 894-E, Monark, US). The load was determined for each subject according to body mass $(0.075 \mathrm{~kg}$ x body weight in $\mathrm{kg}$ ). Seat height was adjusted to each subject's satisfaction and toe-clips were used to prevent the subject's feet from slipping off the pedals. The warm-up period included 3-min pedalling against a 30 Watt constant load. By the command 'start' the participant began pedalling as fast as possible until the end of the test period. Strong motivation was given verbally to subjects during the test.

\section{Biochemical measurements}

Plasma ANP and BNP measurements were done by radioimmunoassay whereas adiponection levels were determined by enzyme linked immunosorbent assay. Commercial kits were used for ANP (RK-005-06, Phoenix Pharmaceuticals, US), BNP (RK-01124, Phoenix Pharmaceuticals, US), and adiponectin (EK-ADI-01, Phoenix Pharmaceuticals, US) measurements based on leaflet inbox instructions. Blood lactate levels were measured by a portable lactate meter (Accutrend Plus, Cobas, Roche Diagnostics, Germany) and test strips (BM-Lactate, Ref. No: 0301654016, Cobas, Roche Diagnostics, Germany). Total cholesterol, high density lipoprotein, and triglyceride levels were measured by spectrophotometry (Beckman Coulter). Low density lipoprotein-cholesterol was calculated according to the Friedewald formula [total cholesterol-(triglyceride/5+ high density lipoprotein)]. Creatinine was evaluated by spectrophotometric autoanalyser (MEGA 600, Merck, Germany) using commercial kits (Diasis, Germany). 


\section{Statistical analysis}

All data were given as means and standard deviations unless otherwise indicated. Normal distribution of variables was tested by One Sample Kolmogorov Smirnov test. Comparison of mean values obtained pre- and post exercise measurements was performed by paired samples t-test for parametric variables, and Wilcoxon signed ranks test for non-parametric variables. Between group comparisons were made by t-test for parametric variables and Mann Whitney $U$ test for non-parametric variables. The analysis of covariance test was used to test the difference between the mean percent changes in both gender groups. Relationship between hormones and hemodynamic measurements was tested by Spearman's correlation analysis. A $\mathrm{p}$ value lower than 0.05 was accepted as statistically significant. Statistical analyses were performed by using the SPSS 20.0 (IBM SPSS Inc., Chicago, IL, USA) statistical software.

\section{Results}

General characteristics of the study group are given in Table 1. All measurements were within normal limits. The mean height, weight and body mass index values were significantly higher in male participants than in females. Fasting blood glucose and blood levels of urea and creatinin were also significantly higher in males than in females. Serum HDL level was significantly lower in men than in women (see Table 1 for details). Measurements during exercise test were given in Table 2. Male participants exerted higher power parameters than females. Wingate anaerobic exercise test led to significant increases in systolic and diastolic blood pressures in both gender (Male SBP, 125.4 \pm 8.4 vs $161.1 \pm 23.8 \mathrm{mmHg}, \mathrm{p}<0.001$; DBP, $68.6 \pm 6.9$ vs $69.2 \pm 9.3$ $\mathrm{mmHg}, \mathrm{p}>0.05$; Female SBP, $114.4 \pm 7.6$ vs $126.5 \pm 11.5 \mathrm{mmHg}$, $\mathrm{p}<0.05$; DBP, $66.0 \pm 4.8$ vs $67.8 \pm 6.6 \mathrm{mmHg}, \mathrm{p}>0.05$ ). Heart rate changes before and after the test were also significant (Male,

Table 1. Demographic, anthropometric and biochemical characteristics of the study group

\begin{tabular}{|l|c|c|c|}
\hline & $\begin{array}{c}\text { Whole study group } \\
(\mathbf{n = 3 1 )}\end{array}$ & $\begin{array}{c}\text { Females } \\
(\mathbf{n = 1 6 )}\end{array}$ & $\begin{array}{c}\text { Males } \\
\text { (n=15) }\end{array}$ \\
\hline Demographic & $20.7 \pm 1.7$ & $19.9 \pm 1.3$ & $21.5 \pm 1.8^{*}$ \\
\hline Age, yr & & & \\
\hline Anthropometric & $1.70 \pm 0.07$ & $1.66 \pm 0.05$ & $1.75 \pm 0.05^{* * *}$ \\
\hline Height, m & $65.2 \pm 12.4$ & $56.2 \pm 4.7$ & $74.8 \pm 10.8^{* * *}$ \\
\hline Weight, kg & $22.1 \pm 2.9$ & $20.3 \pm 1.6$ & $24.1 \pm 2.7^{* * *}$ \\
\hline BMI, kg/m 2 & & & \\
\hline Biochemical & $88.4 \pm 15.5$ & $80.9 \pm 13.0$ & $96.5 \pm 14.2^{* *}$ \\
\hline FBG, mg/dL & $19.6 \pm 4.9$ & $16.7 \pm 3.2$ & $22.8 \pm 4.6^{* * *}$ \\
\hline Urea, mg/dL & $0.70 \pm 0.10$ & $0.67 \pm 0.06$ & $0.87 \pm 0.08^{* * *}$ \\
\hline Creatinin & $22.1 \pm 17.0$ & $16.3 \pm 6.4$ & $28.2 \pm 22.2$ \\
\hline ALT, IU/L & $27.3 \pm 13.5$ & $23.3 \pm 4.6$ & $31.7 \pm 18.2$ \\
\hline AST, IU/L & $97.1 \pm 60.0$ & $78.3 \pm 47.8$ & $117.2 \pm 66.7$ \\
\hline TG, mg/dL & $162.5 \pm 32.1$ & $165.0 \pm 34.6$ & $159.8 \pm 30.2$ \\
\hline Cholesterol, mg/dL & $50.5 \pm 16.2$ & $61.0 \pm 11.9$ & $39.3 \pm 12.3^{* * *}$ \\
\hline HDL, mg/dL & $92.7 \pm 25.0$ & $88.4 \pm 28.0$ & $97.3 \pm 21.2$ \\
\hline LDL, mg/dL & & & \\
\hline
\end{tabular}

Abbreviations: BMI, body mass index; FBG, fasting blood glucose; ALT, alanine transaminase; AST, aspartate transaminase; TG, triglyceride; $H D L$, high density lipoprotein; $L D L$, low density lipoprotein. Comparisons were made between the both gender. ${ }^{*} \mathrm{p}<0.05 ;{ }^{* *} \mathrm{p}<0.01 ;{ }^{* * *} \mathrm{p}<0.001$ 
Table 2. Supramaximal exercise results of the study group

\begin{tabular}{|l|c|c|c|}
\hline Wingate Parameters & $\begin{array}{c}\text { Whole study group } \\
(\mathbf{n = 3 1 )}\end{array}$ & $\begin{array}{c}\text { Females } \\
(\mathbf{n = 1 6 )}\end{array}$ & $\begin{array}{c}\text { Males } \\
(\mathbf{n = 1 5})\end{array}$ \\
\hline Peak Power, W & $660.3 \pm 206.5$ & $482.8 \pm 81.7$ & $837.9 \pm 118.9^{* * *}$ \\
\hline Peak Power, W/kg & $9.89 \pm 1.92$ & $8.54 \pm 1.38$ & $11.25 \pm 1.35^{* * *}$ \\
\hline Mean Power, W & $468.3 \pm 14.89$ & $343.0 \pm 56.8$ & $593.6 \pm 95.4^{* * *}$ \\
\hline Mean Power, W/kg & $6.98 \pm 1.20$ & $6.03 \pm 0.67$ & $7.93 \pm 0.77^{* * *}$ \\
\hline Minimum Power, W & $272.1 \pm 113.7$ & $193.0 \pm 72.3$ & $351.1 \pm 90.2^{* * *}$ \\
\hline Minimum Power, W/kg & $4.08 \pm 1.36$ & $3.52 \pm 1.54$ & $4.64 \pm 0.87^{* *}$ \\
\hline
\end{tabular}

Abbreviation: W, Watt. Comparisons were made between the both gender.

${ }^{*} \mathrm{p}<0.05,{ }^{* *} \mathrm{p}<0.01,{ }^{* * *} \mathrm{p}<0.001$, Mann Whitney U test.

$76 \pm 9$ vs $119 \pm 15 \mathrm{~min}^{-1}$, p $<0.001$; Female, $82 \pm 15$ vs $116 \pm 11 \mathrm{~min}^{-1}$, $\mathrm{p}<0.001)$. The mean plasma adiponectin levels before and after supramaximal exercise session were shown in Figure 1. A single bout supramaximal exercise resulted in a significant increase in plasma adiponectin levels (Pre- and post-exercise adiponectin, $17.45 \pm 4.70 \mu \mathrm{g} / \mathrm{mL}$ vs $31.29 \pm 5.16 \mu \mathrm{g} / \mathrm{mL}$; $\mathrm{p}<0.001)$. Gender stratification had no effect on this change. Both male and female participants showed significant elevation in plasma adiponectin levels $(16.52 \pm 4.53$ vs $30.99 \pm 4.56 ; 18.31 \pm 4.85$ vs $31.57 \pm 5.80$ $\mu \mathrm{g} / \mathrm{mL}$; respectively, $\mathrm{p}<0.001$ for both). Plasma ANP and BNP levels remained similar before and after supramaximal exercise (Figure 2 and 3). Both ANP and BNP levels were higher in female subjects during pre-exercise resting period. Supramaximal exercise test led to increase in ANP and BNP levels in females whereas it led to decrease in both natriuretic peptides in males. However, these changes did not reach to statistically significance level. Hematocrit levels significantly increased by the exercise in females and males $(38.2 \pm 2.6$ vs $39.3 \pm 5.8 \%$, $\mathrm{p}<0.05$ and $45.1 \pm 1.8$ vs $48.3 \pm 2.2 \%, \mathrm{p}<0.001)$. Finally, blood lactate level increased significantly by the anaerobic exercise test in both female and

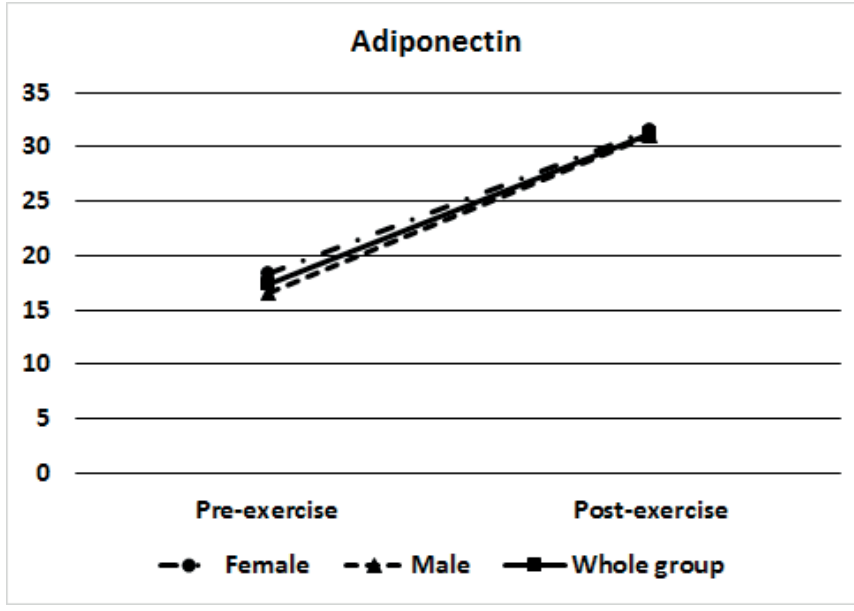

Figure 1. Plasma adiponectine levels before and after supramaximal exercise. A single bout supramaximal exercise resulted in a significant increase in plasma adiponectin levels in male and female subjects ( $p<0.001$ for both).

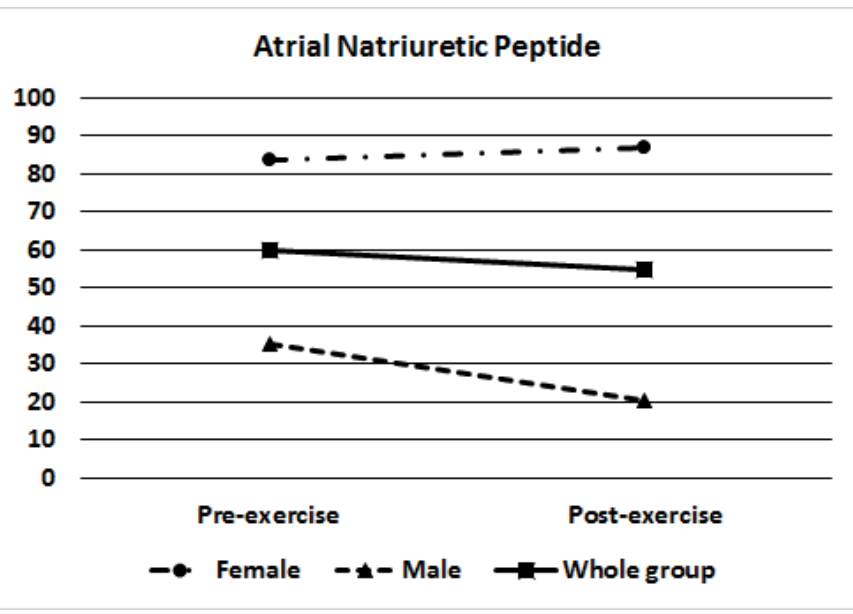

Figure 2. Plasma atrial natriuretic peptide levels remained comparable before and after supramaximal exercise in male and female subjects. 


\section{B-type Natriuretic Peptide}

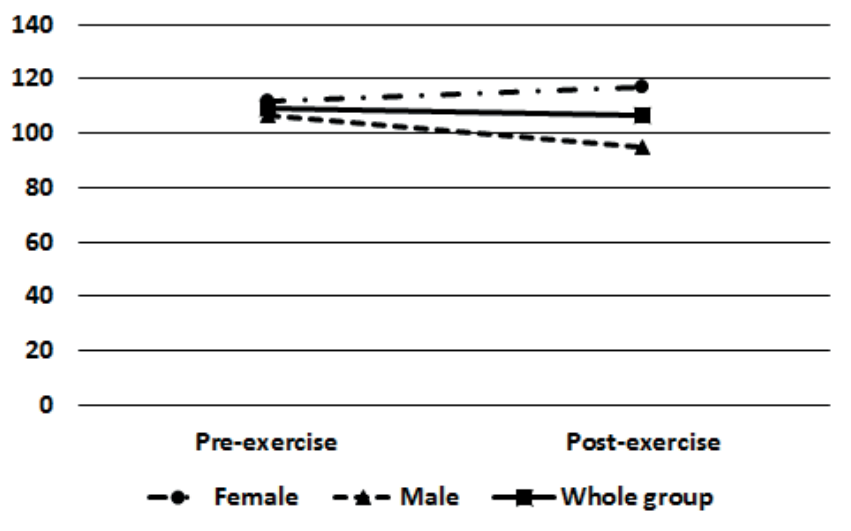

Figure 3. Plasma B-type natriuretic peptide levels remained comparable before and after supramaximal exercise in male and female subjects.

male participants $(2.22 \pm 0.57$ vs $8.58 \pm 2.16$ and $2.46 \pm 1.56$ vs $10.90 \pm 2.91 \mathrm{mmol} / \mathrm{L}, \mathrm{p}<0.001$ for both). Correlation test revealed that systolic and diastolic blood pressure changes during exercise was moderately correlated $(\mathrm{p}=0.02 ; \mathrm{r}=0.41)$. Heart rate and diastolic blood pressure $(\mathrm{p}=0.04 ; \mathrm{r}=0.37)$ and lactate and heart rate changes $(\mathrm{p}=0.01 ; \mathrm{r}=0.43)$ were moderately correlated. ANP, BNP and adiponektin changes were not statistically correlated.

\section{Discussion}

The main finding of this study was a significant increase in plasma adiponectin levels following a 30-second supramaximal exercise test in both male and female subjects, whereas plasma ANP and BNP levels remained unchanged. Exercise induced changes of blood adiponectin were studied previously (13-17). Most of these studies involved long-term chronic exercise programs differed in terms of protocol which included male or female participants. In one of the earlier studies, overweight male participants underwent a 10 -week exercise program comprised of two or three bouts of moderately intense aerobic exercise which caused $260 \%$ rise in adiponectin levels (16). In a following study, young adult healthy females subjected to 30-60 min/ day aerobic exercise for 7 months which in turn led to significant increases in circulating adiponectin levels (15). Another study investigated effects of chronic aerobic training up to 9 months on plasma adiponectin levels and found no significant increase (14). The study group consisted of both male and female workers. There are also some other studies investigated the effects of acute exercise sessions on circulating adiponectin levels. Ferguson et al studied the effects of 60-min aerobic cycle ergometry exercise in healthy subjects and found no change in plasma adiponectin levels of both males and females (18). In a recent study, plasma concentration of adiponectin was not changed in response to one session of acute resistance training (17). Furthermore, having history of regular training was not a significant factor of adiponectin response to exercise (17). Repeated bouts of supramaximal exercise in healthy men resulted in a marked decrease in adiponectin level (13). In our study, participants underwent only single bout 30 -sec supramaximal exercise which led to almost 1.8-fold increase in circulating adiponectin levels. Similarly, plasma adiponectin levels showed a $20 \%$ increase following a 20-min acute intense rowing exercise (19). It is obvious that these studies are not comparable in terms of adiponectin response to acute exercise as each one of them used a different acute exercise protocol. Nevertheless, this study may suggest that adiponectin increases during the very early periods of acute exercise and then returns to pre-exercise levels.

Several putative mechanisms were suggested to explain the link between exercise and alterations in circulating adiponectin levels. Although adiponectin was originally described as an adipokine, we now know that it is also secreted from muscle cells, thus also accepted as myokine (20-22). Adiponectin production in skeletal muscle increases in response to metabolic challenge (23) or acute inflammation caused by lipopolysaccharide injection (24). Acute heavy exercise results in immediate increases in proinflammatory cytokines such as interleukin-6 (13) and C-reactive protein (25) which in turn may induce adiponectin secretion from muscle fibers. Thus, exercise-induced adiponectin rise in circulation may originate from muscle tissue rather than adipose tissue. However, to our knowledge no study has yet examined the mechanism of exercise-induced adiponectin increase.

Another mechanism may involve natriuretic peptides. Tsukamoto et al (26) in their mechanistic study, demonstrated that ANP and BNP enhance adiponectin secretion from cultured human adipocytes. The same group also reported a significant correlation between plasma adiponectin and BNP levels in 1,538 healthy subjects (27). Furthermore, Birkenfeld and colleagues studied the effects of intravenous ANP infusion on systemic adiponectin levels in healthy men (28). They found that ANP acutely increased systemic total and high molecular weight adiponectin concentrations. With all this background, we measured circulating natriuretic peptides and adiponectin levels under conditions of single bout supramaximal exercise. However, we failed to find any significant correlation between exerciseinduced ANP, BNP and adiponectin changes which suggests adiponectin increase may not be related with natriuretic peptides.

We performed a gender-based stratification during the analyses of data. Pre-exercise natriuretic peptide levels were higher 
in female group whereas adiponectin levels were comparable in both groups. In this study, a 30-second supramaximal exercise was ineffective in altering serum ANP and BNP concentrations. However, natriuretic peptide response to exercise was slightly different in male group in which a trend of decrease was observed both in ANP and BNP. In contrast, these were remained unchanged in female participants. Both male and female participants showed similar pattern of increase in adiponectin response to 30-sec supramaximal exercise.

In conclusion, this is the first study which evaluated adiponectin, ANP and BNP levels before and after a 30-sec supramaximal exercise in healthy female and male subjects. These results showed that a 30 -sec supramaximal exercise session enhanced circulating adiponectin levels in both gender groups, whereas ANP and BNP levels exerted non-significant alterations. We suggest that there may be two possibilities in explaining adiponectin increase. First, adiponectin release in response to acute heavy exercise may stem from muscle cells rather than adipose cells. Second, adipocyte mediated adiponectin release may not involve natriuretic peptide secretion.

\section{Acknowledgements}

This study was supported by a grant of Trakya University Scientific Research Projects (Project number TÜBAP-201068).

Conflict of interest statement: The authors declare that the research was conducted in the absence of any commercial or financial relationships that could be construed as a potential conflict of interest.

\section{References}

1. Clerico A, Vittorini S. The cardiac natriuretic hormone system. In: A. Clerico, M. Emdin, editors. Natriuretic Peptides: The Hormones of the Heart. Springer-Verlag, Italia, 2006, pp. 21-64.

2. Kruger S, Graf J, Kunz D, Stickel T, Hanrath P, Janssens U. Brain natriuretic peptide levels predict functional capacity in patients with chronic heart failure. J Am Coll Cardiol 2002;40:718-722. DOI: 10.1016/S0735-1097(02)02032-6

3. Friedl W, Mair J, Thomas S, Pichler M, Puschendorf B. Relationship between natriuretic peptides and hemodynamics in patients with heart failure at rest and after ergometric exercise. Clin Chim Acta 1999;281:121-126. DOI: 10.1016/S0009-8981(98)00217-4

4. Kato M, Kinugawa T, Ogino K, Endo A, Osaki S, Igawa $\mathrm{O}$, et al. Augmented response in plasma brain natriuretic peptide to dynamic exercise in patients with left ventricular dysfunction and congestive heart failure.
J Intern Med 2000;248:309-315. DOI: 10.1046/j.13652796.2000.00736.x

5. Ohba H, Takada H, Musha H, Nagashima J, Mori N, Awaya $\mathrm{T}$, et al. Effects of prolonged strenuous exercise on plasma levels of atrial natriuretic peptide and brain natriuretic peptide in healthy men. Am Heart J 2001;141:751-758. DOI: 10.1067/mhj. 2001.114371

6. Löwbeer C, Seeberger A, Gustafsson SA, Bouvier F, Hulting J. Serum cardiac Troponin T, Troponin I, plasma BNP and left ventricular mass index in professional football players. J Sci Med Sport 2007;10:291-296. DOI: 10.1016/j.jsams. 2006.10.002

7. Lafontan M, Moro C, Sengenes C, Galitzky J, Crampes F, Berlan M. An unsuspected metabolic role for atrial natriuretic peptides: the control of lipolysis, lipid mobilization, and systemic nonesterified fatty acids levels in humans. Arterioscler Thromb Vasc Biol 2005;25:2032-2042. DOI: 10.1161/01.ATV. 0000183728.14712.d8

8. Dessi-Fulgheri P, Sarzani R, Rappelli A. Role of the natriuretic peptide system in lipogenesis/lipolysis. Nutr Metab Cardiovasc Dis 2003;13:244-249. DOI: 10.1016/ S09394753(03)80018-2

9. Sengenes C, Moro C, Galitzky J, Berlan M, Lafontan M. Natriuretic peptides: a new lipolytic pathway in human fat cells. Med Sci (Paris) 2005;21:61-65. DOI: 10.1051/medsci/200521161

10. Tanaka T, Tsutamoto T, Sakai H, Nishiyama K, Fujii M, Yamamoto $\mathrm{T}$, et al. Effect of atrial natriuretic peptide on adiponectin in patients with heart failure. Eur J Heart Fail 2008;10:360-366. DOI: 10.1016/j.ejheart.2008.02.005

11. Haugen E, Furukawa Y, Isic A, Fu M. Increased adiponectin level in parallel with increased NT-Pro BNP in patients with severe heart failure in the elderly: A hospital cohort study. Int J Cardiol 2008;125:216-219. DOI: 10.1016/j.ijcard.2007.12. 002

12. Öztürk L, Bulut E, Vardar SA, Uzun C. Effects of sleep deprivation on anaerobic exercise-induced changes in auditory brainstem evoked potentials. Clin Physiol Funct Imaging 2007;27:263-267. DOI: 10.1111/j.1475-097X.2007.00746.x

13. Gokbel H, Okudan N, Gul I, Belviranlı M, Gergerlioglu HS, Basaralı MK. Effects of repeated bouts of supramaximal exercise on plasma adiponectin, interleukin- 6 and tumor necrosis factor- $\alpha$ levels in sedentary men. J Strength Cond Res 2012;26:1675-1679. DOI: 10.1519/JSC.0b013e31823ac1c

14. Guo W, Kawano H, Piao L, Itoh N, Node K, Sato T. Effects of aerobic exercise on lipid profiles and high molecular weight adiponectin japanese workers. Intern Med 2011;50:389-395. DOI: 10.2169/internalmedicine.50.4380 
15. Kondo T, Kobayashi I, Murakami M. Effect of exercise on circulating adipokine levels in obese young women. Endocrine J 2006;53:189-195. DOI: 10.1507/endocrj. 53.189

16. Kriketos AD, Gan SK, Poynten AM, Furler SM, Chisholm DJ, Campbell LV. Exercise increases adiponectin levels and insulin sensitivity in humans. Diabetes Care 2004;27:629630. DOI: 10.2337/diacare.27.2.629

17. Mansouri M, Keshtkar A, Hsani-Ranjbar S, Far ES, Tabatabaei-Malazy O, Omidfar K, et al. The impact of one session resistance exercise on plasma adiponectin and RBP4 concentration in trained and untrained healthy young men. Endocrine J 2011;58:861-868. DOI: 10.1507/endocrj.EJ110046

18. Ferguson MA, White LJ, McCoy S, Kim HW, Petty T, Wilsey J. Plasma adiponectin response to acute exercise in healthy subjects. Eur J Appl Physiol 2004;91:324-329. DOI: 10.1007/ s00421-003-0985-1

19. Jürimae J, Purge $P$, Jürimae T. Adiponectin is altered after maximal exercise in highly trained male rowers. Eur J Appl Physiol 2005;93:502-505. DOI: 10.1007/ s00421-004-1238-7

20. Amin RH, Mathews ST, Camp HS, Ding L, Leff T. Selective activation of PPAR $\gamma$ in skeletal muscle induces endogenous production of adiponectin and protects mice from dietinduced insulin resistance. Am J Physiol 2010;298:E28-37. DOI: 10.1152/ajpendo.00446.2009

21. Krause MP, Liu Y, Vu V, Chan L, Xu A, Riddell MC, et al. Adiponectin is expressed by skeletal muscle fibers and influences muscle phenotype and function. Am J Physiol 2008; 295:C203. DOI: 10.1152/ajpcell.00030.2008

22. Liu Y, Chewchuk S, Lavigne C, Brûle S, Pilon G, Houde V, et al. Functional significance of skeletal muscle adiponectin production, changes in animal models of obesity and diabetes, and regulation by rosiglitazone treatment. Am J Physiol 2009;297:E657-64. DOI: 10.1152/ajpendo.00186.2009

23. Jortay J, Senou M, Abou-Samra M, Noel L, Robert A, Many MC, et al. Adiponectin and skeletal muscle: Pathophysiological implications in metabolic stress. Am J Pathol 2012;181:245-256. DOI: 10.1016/ajppath.2012.03.035

24. Delaigle AM, Jonas JC, Bauche IB, Cornu O, Brichard SM. Induction of adiponectin in skeletal muscle by inflammatory cytokines: in vivo and in vitro studies. Endocrinology 2004; 145:5589-5597. DOI: 10.1210/en.2004-0503

25. Chen YW, Apostolakis S, Lip GYH. Exercise-induced changes in inflammatory processes: Implications for thrombogenesis in cardiovascular disease. Ann Med 2014; 46:439455. DOI: $10.3109 / 07853890.2014 .927713$

26. Tsukamoto O, Fujita M, Kato M, Yamazaki S, Asano Y, Ogai A, et al. Natriuretic peptides enhance the production of adiponectin in human adipocytes and in patients with chronic heart failure. J Am Coll Cardiol 2009; 53:2070-2077. DOI: 10.1016/j.jacc. 2009.02.038

27. Ohara T, Kim J, Asakura M, Asanuma H, Nakatani S, Hashimura $\mathrm{K}$, et al. Plasma adiponectin is associated with plasma brain natriuretic peptide and cardiac function in healthy subjects. Hypertens Res 2008; 31:825-831. DOI: 10.1291/hypres.31.825

28. Birkenfeld AL, Boschmann M, Engeli S, Moro C, Arafat A, Luft FC, et al. Atrial natriuretic peptide and adiponectin interactions in man. PLoS One 2012; 7:e43238. DOI: 10.1371/ journal.pone.0043238 